\title{
On the Design \\ of Solar Energy Tracker System
}

\author{
Oloka Reagan Otieno ${ }^{a}$ and Mohanad Abdulhamid ${ }^{b}$ \\ ${ }^{a}$ University of Nairobi \\ Kenya \\ ${ }^{b}$ AL-Hikma University

Received 12.07.2021, received in revised form 14.08.2021, accepted 21.09.2021

\begin{abstract}
Solar energy is a very important means of renewable energy resource. With solar tracking, it will become possible to generate more energy since the solar panel can maintain a perpendicular profile to the rays of the sun. Even though the initial cost of setting up the tracking system is considerably high, there are cheaper options that have been proposed over time. This paper discusses the design and construction of a prototype for solar tracking system that has a single axis of freedom. Light dependent resistors (LDRs) are used for sunlight detection. The control circuit is based on an ATMega328P microcontroller. It was programmed to detect sunlight via the LDRs before actuating the servo to position the solar panel. The solar panel is positioned where it is able to receive maximum light. As compared to other motors, the servo motors are able to maintain their torque at high speed. They are also more efficient with efficiencies in the range of 80-90\%. Servos can supply roughly twice their rated torque for short periods. They are also quiet and do not vibrate or suffer resonance issues. Performance and characteristics of solar panels are analyzed experimentally.
\end{abstract}

Keywords: Solar energy tracker; solar panel.

(C) Siberian Federal University. All rights reserved

This work is licensed under a Creative Commons Attribution-Non Commercial 4.0 International License (CC BY-NC 4.0).

* Corresponding author E-mail address: researcher12018@yahoo.com, moh1hamid@yahoo.com 


\title{
О проекте системы солнечной энергии
}

\author{
Олока Рейган Отиено ${ }^{a}$ Моханад Абдулхамид

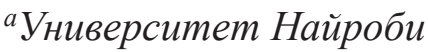 \\ Кения \\ ${ }^{\sigma}$ AL-Университет Хикма \\ Ирак, Багдад
}

\begin{abstract}
Аннотация. Солнечная энергия - один из важных возобновляемых источников энергии, позволяющий генерировать большое ее количество, если солнечная панель расположена перпендикулярно к лучам солнца. Как правило, первоначальные затраты на создание самой системы значительны, однако со временем появились более дешевые варианты. В данной статье рассмотрено проектирование и построение прототипа системы (трекера) солнечных панелей, которая имеет одну ось свободы. Для обнаружения солнечного света здесь используют маломощные резисторы (LDRS). Схема управления основана на микроконтроллере ATMEGA328P, который запрограммирован для обнаружения солнечного света с применением сервопривода для позиционирования солнечной панели. Солнечная панель расположена там, где он может получить максимальный свет. По сравнению с другими моторами серводвигатели могут поддерживать крутящий момент на высокой скорости с эффективностью в диапазоне 80 $90 \%$. Сервоприводы могут обеспечивать примерно вдвое больше обычного номинального крутящего момента в течение коротких периодов. Кроме того, они работают бесшумно, не вибрируют и не создают резонанса. Производительность и характеристики солнечных батарей анализируются экспериментально.
\end{abstract}

Ключевые слова: система солнечного трекера, солнечная панель.

Цитирование: Отиено, Олока Рейган. О проекте системы солнечной энергии / Олока Рейган Отиено, Моханад Абдулхамид // Журн. Сиб. федер. ун-та. Техника и технологии, 2021, 14(6). С. 689-702. DOI: 10.17516/1999-494X-0343

\section{Introduction}

Solar energy is clean and available in abundance. Solar technologies use the sun for provision of heat, light and electricity. These are for industrial and domestic applications. With the alarming rate of depletion of major conventional energy sources like petroleum, coal and natural gas, coupled with environmental caused by the process of harnessing these energy sources, it has become an urgent necessity to invest in renewable energy sources that can power the future sufficiently. The energy potential of the sun is immense. Despite the unlimited resource however, harvesting it presents a challenge because of the limited efficiency of the array cells.

The best efficiency of the majority of commercially available solar cells ranges between 10 and 20 percent. This shows that there is still room for improvement. This paper seeks to identify a way of improving efficiency of solar panels using solar tracking. The tracking mechanism moves and positions the solar array such that it is positioned for maximum power output. Other ways include identifying sources of losses and finding ways to mitigate them.

When it comes to the development of any nation, energy is the main driving factor. There is an enormous quantity of energy that gets extracted, distributed, converted and consumed every single day in the global society. Fossil fuels account for around 85 percent of energy that is produced. Fossil fuel resources are limited and using them is known to cause global warming because of emission of 
greenhouse gases. There is a growing need for energy from such sources as solar, wind, ocean tidal waves and geothermal for the provision of sustainable and power.

Solar panels directly convert radiation from the sun into electrical energy. The panels are mainly manufactured from semiconductor materials, notably silicon. Their efficiency is $24.5 \%$ on the higher side. Three ways of increasing the efficiency of the solar panels are through increase of cell efficiency, maximizing the power output and the use of a tracking system.

Maximum power point tracking (MPPT) is the process of maximizing the power output from the solar panel by keeping its operation on the knee point of power-voltage $(\mathrm{P}-\mathrm{V})$ characteristics. MPPT technology will only offer maximum power which can be received from stationary arrays of solar panels at any given time. The technology cannot however increase generation of power when the sun is not aligned with the system.

Solar tracking is a system that is mechanized to track the position of the sun to increase power output by between $30 \%$ and $60 \%$ than systems that are stationary. It is a more cost effective solution than the purchase of solar panels.

There are various types of trackers that can be used for increase in the amount of energy that can be obtained by solar panels. Dual axis trackers are among the most efficient, though this comes with increased complexity. Dual trackers track sunlight from box axes. They are the best option for places where the position of the sun keeps changing during the year at different seasons. Single axis trackers are a better option for places around the equator where there is no significant change in the apparent position of the sun.

The level to which the efficiency is improved will depend on the efficiency of the tracking system and the weather. Very efficient trackers will offer more efficiency because they are able to track the sun with more precision. There will be bigger increase in efficiency in cases where the weather is sunny and thus favorable for the tracking system. Several works which discuss the solar energy tracker system are found in [1-6].

This paper is undertaken to ensure the rays of the sun are falling perpendicularly on the solar panel to give it maximum solar energy. This is harnessed into electrical power. Maximum energy is obtained between $1200 \mathrm{hrs}$ and $1400 \mathrm{hrs}$, with the peak being around midday. At this time, the sun is directly overhead. At the same time, the least energy will be required to move the panel, something that will further increase efficiency of the system. The paper is designed to address the challenge of low power, accurate and economical microcontroller based tracking system which is implemented within the allocated time and with the available resources. It is supposed to track the sun's movement in the sky. In order to save power, it is supposed to sleep during the night by getting back into an horizontal position. There is implementation of an algorithm that solves the motor control that is then written into C- program on Arduino IDE.

\section{Design and implementation}

\subsection{Light Sensor Theory and Circuit of Sensor Used}

Light detecting sensor that maybe used to build solar tracker include; phototransistors, photodiodes, LDR and linear light sensor(LLS05). A suitable, inexpensive, simple and easy to interface photo sensor is analog LDR which is the most common in electronics. It is usually in form of a photo resistor made of cadmium sulfide (CdS) or gallium arsenide (GaAs). Next in complexity is the photodiode followed by the phototransistor. 


\subsection{Light Dependent Resistor Theory}

LDR shown in Fig. 1 is simplest optical sensor that is a photon resistor or photocell which is a light sensitive resistor these are made of two types, cadmium sulfide (CdS) and gallium arsenide (GaAs).

The sun tracker system designed here uses two cadmium sulfide (CdS) photocells for sensing the light. The photocell is a passive component whose resistance is inversely proportional to the amount of light intensity directed towards it. It is connected in series with capacitor.

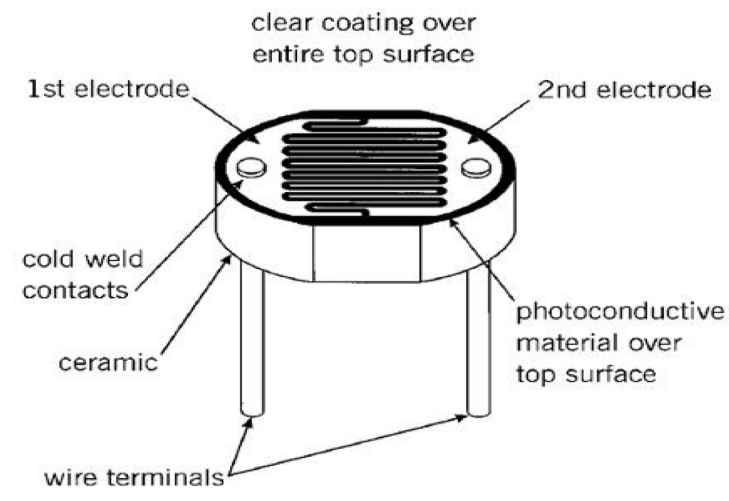

Fig. 1. LDR construction

The photocell to be used for the tracker is based on its dark resistance and light saturation resistance. The term light saturation means that further increasing the light intensity to the CdS cells will not decrease its resistance any further. Light intensity is measured in Lux, the illumination of sunlight is approximately 30,000 lux.

Normally the resistance of an LDR is very high, sometimes as high as $1000000 \mathrm{ohms}$, but when they are illuminated with light resistance drops dramatically. When the light level is low the resistance of the LDR is high. This prevents current from flowing to the base of the transistors. Consequently the light emitting diode(LED) does not light. However, when light shines onto the LDR its resistance falls.

\subsubsection{The concept of using two LDRs}

Concept of using two LDRs for sensing is illustrated in Fig. 2. The stable position is when the two LDRs having the same light intensity. When the light source moves, i. e. the sun moves from west to east, the level of intensity falling on both the LDRs changes and this change is calibrated into voltage using voltage dividers. The changes in voltage are compared using built-in comparator of microcontroller and motor is used to rotate the solar panel in a way so as to track the light source.

\subsection{Light sensor design}

The solar tracker makes use of a Cds photocell for detecting light. There was use of a complementary resistor with a value of $10 \mathrm{k}$. With the resulting configuration, the output voltage will increase with increase in light intensity. The value of the complementary resistor is chosen such that the widest 


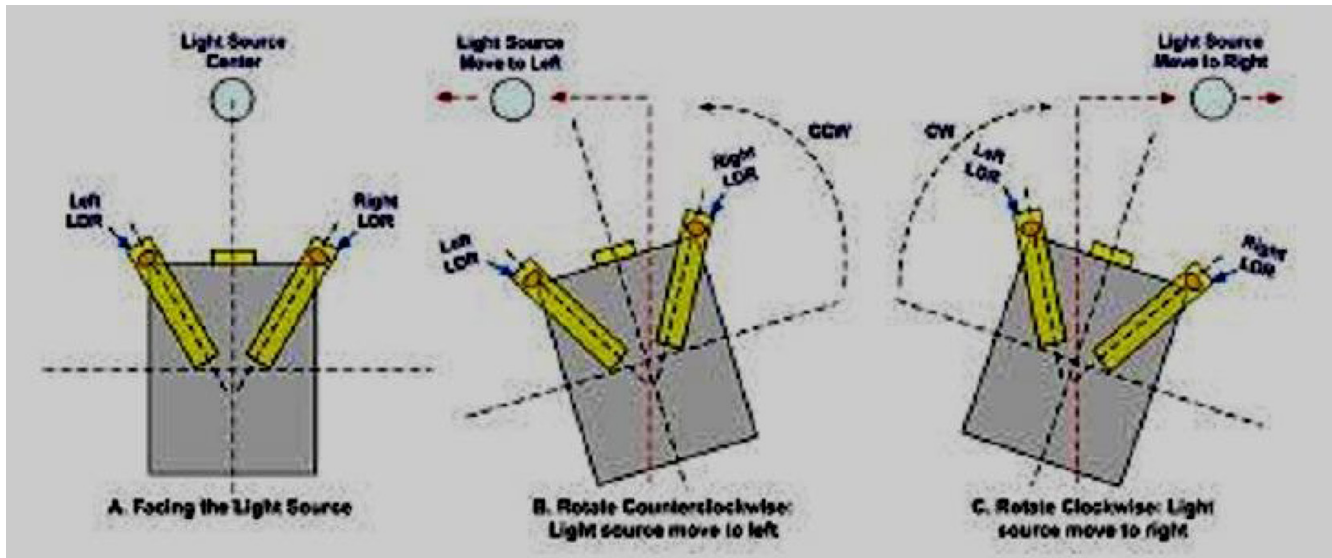

Fig. 2. Use of two LDRs

Table 1. Photocell Resistance Testing Data

\begin{tabular}{|c|l|}
\hline Measured Resistance & \multicolumn{1}{|c|}{ Comment } \\
\hline $50 \mathrm{~K} \Omega$ & Dark light conditions (black vinyl tape placed over cell) \\
\hline $4.35 \mathrm{~K} \Omega$ & Average light conditions (normal room lighting level) \\
\hline $200 \Omega$ & Bright light conditions (flashlight directly in front of cell) \\
\hline
\end{tabular}

output range is achieved. The photocell resistance is measured under bright light, average light and dark light conditions. The results are listed in the Table 1 below.

The voltage divider circuit formed is shown in Fig. 3 below.

From the given relationship, the input-output relationship for the voltage divider circuit is given by:

$$
V_{i}=V_{c c}\left\{R_{p o t} /\left(L D R+R_{p o t}\right)\right\}
$$

where,

$\mathrm{V} i=$ Input voltage into the microcontroller $\mathrm{R}_{\text {pot }}=$ Resistance of the potentiometer which is $10 \mathrm{~K} \mathrm{~V}_{\mathrm{cc}}=$ Supply voltage to microcontroller and LDRs

\subsection{Servo motor}

Servo motors are used for various applications. They are normally small in size and have good energy efficiency. The servo circuitry shown in Fig. 4 is built inside the motor unit and comes with a positionable shaft that is fitted with a gear. The motor is controlled with an electric signal that determines the amount of shaft movement.

\subsection{Crystal}

Crystal oscillators are electronic oscillator circuits that use inverse piezoelectric effect. With this effect, when electric field is applied across certain materials they will produce mechanical deformation. 


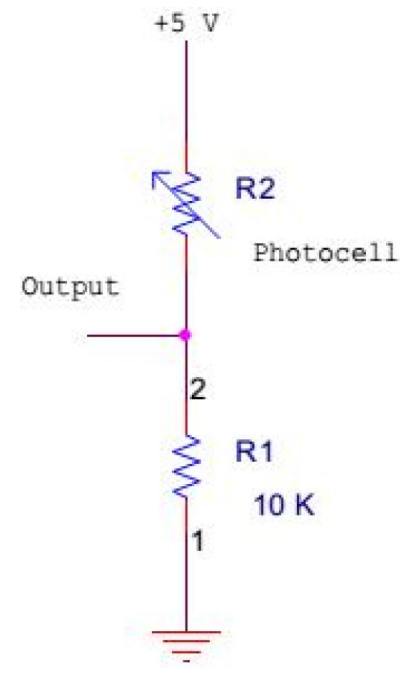

Fig. 3. The input circuit that employs a voltage divider

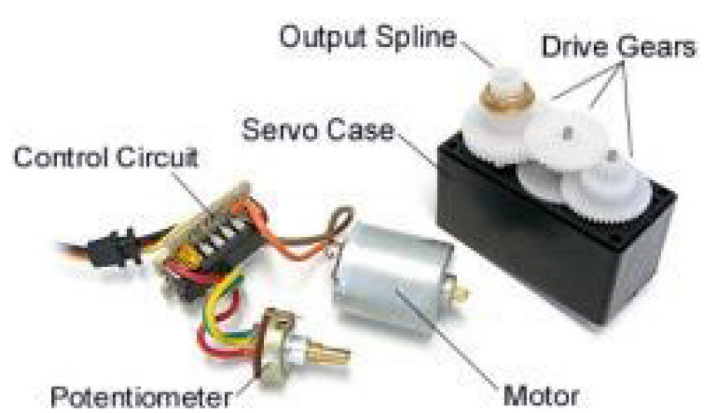

Fig. 4. Servo motor inside features

Therefore a crystal uses mechanical resonance of a vibrating crystal of piezoelectric material so that there is creation of an electric signal with precise frequency. They have high stability, low cost and high quality factor which makes them superior over such resonators as inductance-capacitance(LC) circuits, ceramic resonators and turning forks. The crystal action can be represented by an equivalent electrical resonant circuit as shown in Fig. 5.

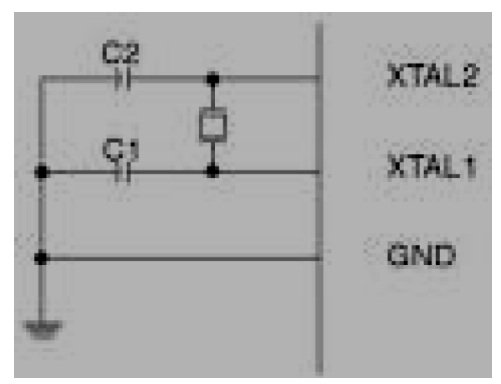

Fig. 5. Circuit diagram of a crystal

The optimal values of the capacitors depend on whether a quartz crystal or ceramic resonator is being used. It will also depend on application-specific requirements on start-up time and frequency tolerance. Crystal oscillators are not built into integrated circuits(ICs) because they cannot be easily fabricated with IC processes and the size is physically larger than IC circuits.

The internal oscillators of microcontrollers are RC oscillators. The reason why crystal oscillators are used is because the quality factor is on the order of 100000 while that of RC oscillators is on the order of 100. Therefore, the crystal oscillator has lower phase noise and lower variation in output frequency. 


\subsection{Voltage regulation}

Voltage regulators are designed to automatically maintain voltages at a constant level. The LM7805 voltage regulator used is shown in Fig. 6. It is a member of the $78 \mathrm{xx}$ series of fixed linear

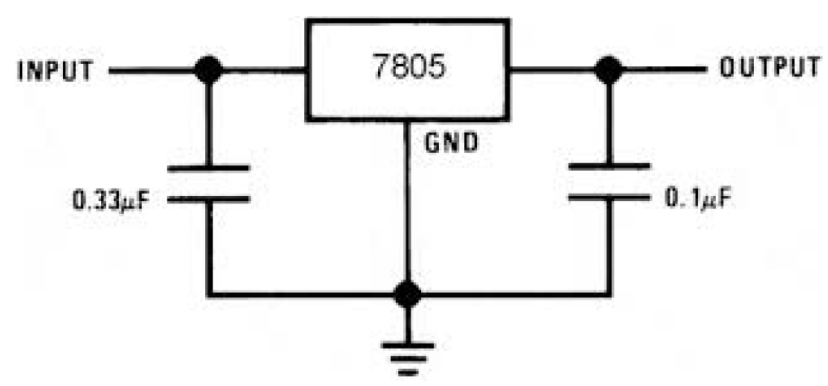

Fig. 6. Voltage regulator circuit LM7805

voltage regulator ICs. Voltage sources in circuits could be having fluctuations and thus not be able to give fixed voltage output. The voltage regulator IC maintains the output voltage at a value that is constant. The LM 7805 provides $+5 \mathrm{~V}$ regulated power supply. Capacitors are connected at the input and output depending on respective levels of voltage.

\subsection{Microcontroller}

Microcontroller is a single chip microcomputer made through very-large-scale-integration(VLSI) fabrication. A microcontroller also called an embedded controller because the microcontroller and its support circuits are often built into, or embedded in, the devices they control. A microcontroller is available in different word lengths like microprocessors (4bit,8bit,16bit,32bit,64bit and 128 bit microcontrollers are available today).

A microcontroller contains one or more of the following components:

- Central processing unit (CPU)

- Random Access Memory (RAM)

- Read Only Memory (ROM)

- Input/Output ports

- Timers and Counters

- Interrupt controls

- Analog to digital converters

- Digital analog converters

- Serial interfacing ports

- Oscillatory circuits

Microcontrollers need to be programmed to be capable of performing anything useful. It then executes the program loaded in its flash memory. The code comprised of a sequence of zeros and ones. It is organized in 12-, 14- or 16-bit wide words, depending on the microcontroller's architecture. Every word is considered by the CPU as a command being executed during the operation of the microcontroller. 


\subsubsection{ATmega328P}

The ATmega328P is a low-power CMOS8-bit microcontroller based on the AVR enhanced reduced instruction set computing(RISC) architecture. By executing powerful instructions in a single clock cycle, the ATmega328P achieves throughputs approaching 1 MIPS per MHz allowing the system designer to optimize power consumption versus processing speed.

It has 28 pins. There are 14 digital I/O pins from which 6 can be used as pulse width modulation(PWM) outputs and 6 analog input pins. The I/O pins account for 20 of the pins. The 20 pins can act as input to the circuit or as output. Whether they are input or output is set in the software.

Two of the pins are for the crystal oscillator and are supposed to provide a clock pulse for the Atmega chip. The clock pulse is needed for synchronization so that communication occurs in synchrony between the Atmega chip and a device connected to it. Two of the pins, Vec and GND are for powering the chip. The microcontroller requires between $1.8-5.5 \mathrm{~V}$ of power to operate. The pin-out for the microcontroller is shown in Fig. 7, and its details found in[2].

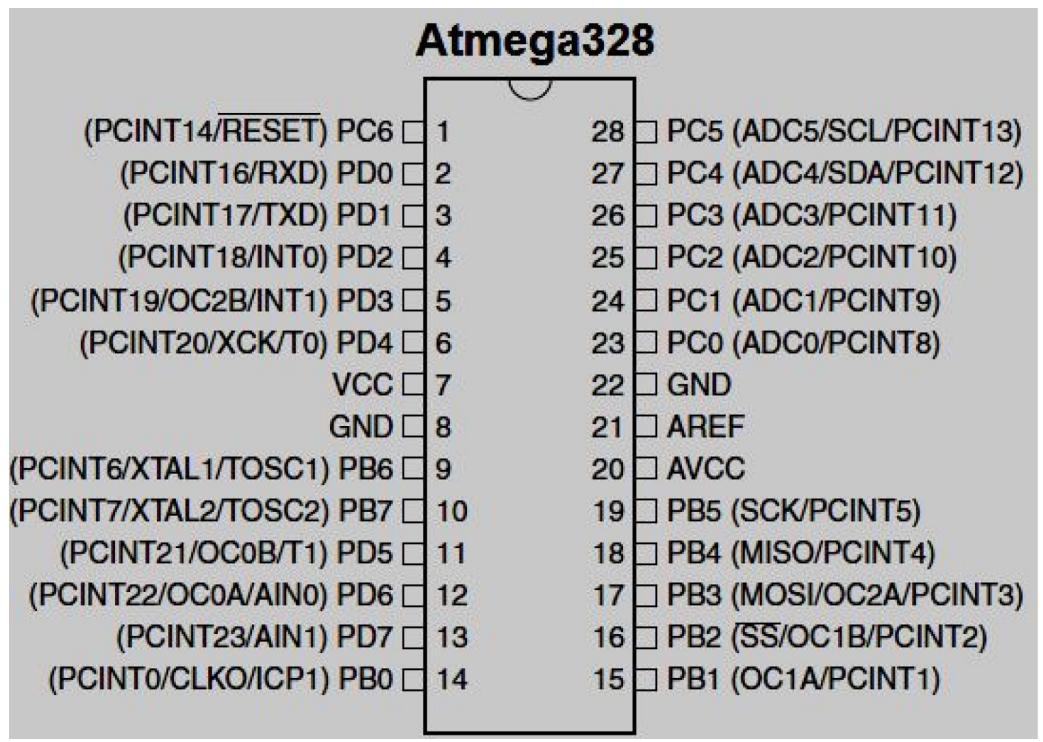

Fig. 7. Atmega 328P

\subsection{The design tool}

The software design is done using Arduino IDE which is used for the programming. The program is written using the $\mathrm{C}$ language. The Proteus circuit editing software is used for drawing the printed circuit board(PCB) circuit. The design of the circuit is done using Eagle software.

\subsection{Algorithm for Motor Control}

The algorithm gives the description of the general steps below:

1. There is input of the voltages from the two LDRs.

2. The inputs are analog. They are converted to digital values that range between $0-1023$.

3. The two digital values are compared and the difference between them obtained. 
4. The difference between the values obtained is the error proportional angle for the rotation of the servo motor.

5. If the LDR voltages are the same, the servo stops. Otherwise, the servo rotates until the difference is the same.

The inputs into the system are the two LDR voltages into pins 23 and 24 of the Atmega328P. There is then the conversion of the analog voltages into their digital values. The larger of the two signals is sent to the circuit which drives the DC motor to the direction with more light intensity. The hardware diagram of the solar tracking system is shown Fig. 8.

After that, all the components are assembled. The input stage comprises the LDRs which feed the voltage outputs to the microcontroller. From the LDRs are potentiometers that are used for varying the resistance. When there is plenty of sunshine, the potentiometers are adjusted to their maximum value that is $10 \mathrm{~K}$. For days when the weather is not very sunny, the resistance is reduced by varying the potentiometer to ensure readings are more easily taken. The LDRs are connected to pins 4 and 5 .

The embedded software design has the $\mathrm{C}$ code loaded into the Atmega328P. The resistor $\mathrm{R} 1$ is a pull up resistor for preventing the microcontroller from continually resetting.

Pins 8 and 22 are grounded as specified by the specifications of the microcontroller. Digital pin 9 is connected to the signal pin of the servo motor and serves to control the movement of the servo. There is also the power pin of the servo that is connected to power. The last servo pin is grounded. Pins 9 and 10 are for the quartz crystal. There are various switches that control the powering of different components. The LED indicates when the circuit is powered and the entire system is functional.

There is a reset button for positioning the panel to an initial position which is at an inclination of 40 degrees. This is done preferably in the evening after the sun has set. It makes the LDR go back to an

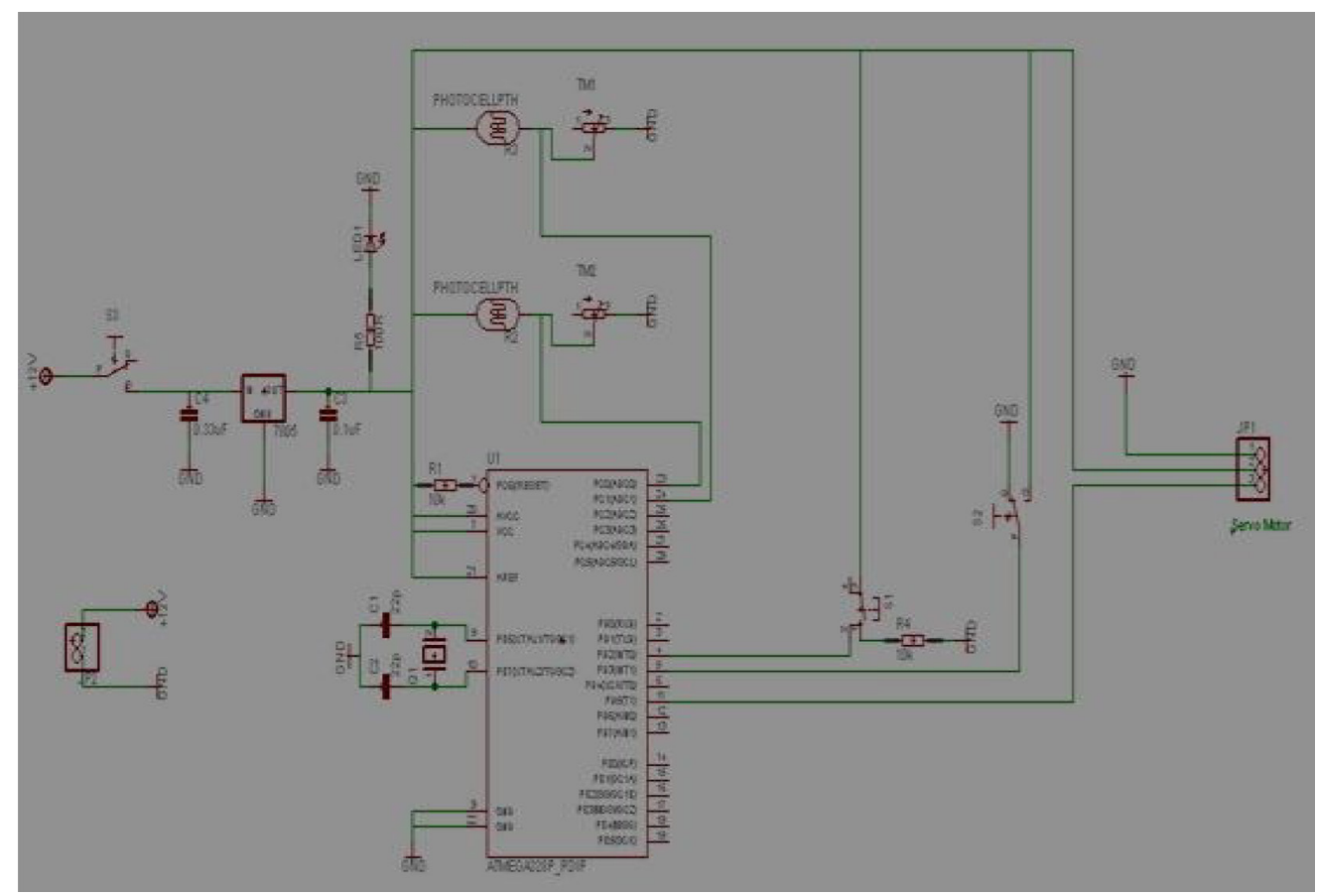

Fig. 8. Hardware diagram of solar tracking system 
initial position, ready for tracking sunlight on the next day. There is also a push button for initializing the servo motor. It switches it on, leaving it on standby mode. Pins 7, 20 and 21 are for powering the microcontroller. It requires $5 \mathrm{~V}$. The inputs to the LDR are simulated.

\section{Results and Analysis}

\subsection{Results}

The results were gotten from LDRs for the solar tracking system and the panel that has a fixed position. The results were recorded for four days, recorded and tabulated. The outputs of the LDRs were dependent on the light intensity falling on their surfaces. Arduino has a serial that communicates on digital pins 0 (RX) and 1 (TX) as well as with the computer through a universal serial bus(USB). If these functions are thus used, pins 0 and 1 can be used for digital input or output.

Arduino environment's built in serial monitor can be used to communicate with the arduino board. To collect the results, a code was written that made it possible to collect data from the LDRs after every one hour. The electrical erasable programmable read only memory(EEPROM) came in handy in this. It is the memory whose values are kept when the board is turned off. The values from the two LDRs are to be read and recorded at the given intervals.

The LDRs measure the intensity of light and therefore they are a valid indication of the power that gets to the surface of the solar panel. As a result, by measuring the light intensity at a given time, it will be possible to get the difference in efficiency between the tracking panel and the fixed one. The light intensity is directly proportional to the power output of the solar panel.

To get the values at the end of the day, the Arduino board was used to connect the microcontroller to the computer. The RX and TX pins are used for the connection. The code for reading the values that were recorded is loaded into the microcontroller. The various values are obtained and converted into volts. The Vcc to the microcontroller and the LDRs is 5volts. The Atmega 328P has 1024 voltage steps and 5 volts. When they are converted into digital values, the values will be in the range of $0-1023$. The conversion is done using the relation below.

\section{LDR Output $=$ Equivalent digital output $* 5 / 1023$ Volts}

The results were obtained for different days. Getting results from different days was helpful in that it made it possible to compare the various values gotten from different weather conditions. Three weather conditions are considered; 1-cloudy morning and sunny afternoon; 2-bright sunny; 3 -cloudy day. The values obtained were recorded in Tables 2 to Table 4 and used to draw graphs in Fig. 9 to Fig. 11.

Key points to note:

LDR1 is the photo resistor 1 reading for a solar panel that is fixed. LDR2 indicates the $2^{\text {nd }}$ photo resistor for a fixed solar panel.

LDR12 indicates the $1^{\text {st }}$ photo resistor reading in the tracking solar panel.

LDR22 indicates the $2^{\text {nd }}$ photo resistor for a tracking solar panel.

\subsection{Analysis}

From the Figs.9-11, it can be seen that the maximum sunlight occurs at around midday, with maximum values obtained between 1200 hours and 1400 hours. In the morning and late evening, 
Table 2. Results for cloudy morning and sunny afternoon for $6^{\text {th }}$ and $7^{\text {th }}$ April 2017

\begin{tabular}{|c|c|c|c|c|}
\hline & \multicolumn{2}{|c|}{ LDR readings for Fixed Panel } & \multicolumn{2}{c|}{ LDR readings for a Tracking Panel } \\
\hline Time & LDR1 & LDR2 & LDR12 & 1.487 \\
\hline $0630 \mathrm{Hrs}$ & 0.196 & 0.176 & 1.804 & 1.839 \\
\hline $0730 \mathrm{Hrs}$ & 0.249 & 0.210 & 2.757 & 2.933 \\
\hline $0830 \mathrm{Hrs}$ & 0.225 & 0.196 & 3.631 & 3.783 \\
\hline $0930 \mathrm{Hrs}$ & 0.723 & 0.567 & 3.900 & 3.798 \\
\hline $1030 \mathrm{Hrs}$ & 0.733 & 0.816 & 3.910 & 3.969 \\
\hline $1130 \mathrm{Hrs}$ & 3.211 & 2.297 & 4.990 & 4.990 \\
\hline $1230 \mathrm{Hrs}$ & 4.888 & 4.941 & 4.985 & 4.990 \\
\hline $1330 \mathrm{Hrs}$ & 3.803 & 3.910 & 4.976 & 4.985 \\
\hline $1430 \mathrm{Hrs}$ & 3.456 & 4.057 & 4.941 & 4.892 \\
\hline $1530 \mathrm{Hrs}$ & 3.930 & 3.846 & 4.824 & 4.594 \\
\hline $1630 \mathrm{Hrs}$ & 1.999 & 1.544 & 3.128 & 2.981 \\
\hline $1730 \mathrm{Hrs}$ & 1.090 & 1.144 & 0.982 & 0.968 \\
\hline $1830 \mathrm{Hrs}$ & 0.718 & 0.787 & & \\
\hline
\end{tabular}

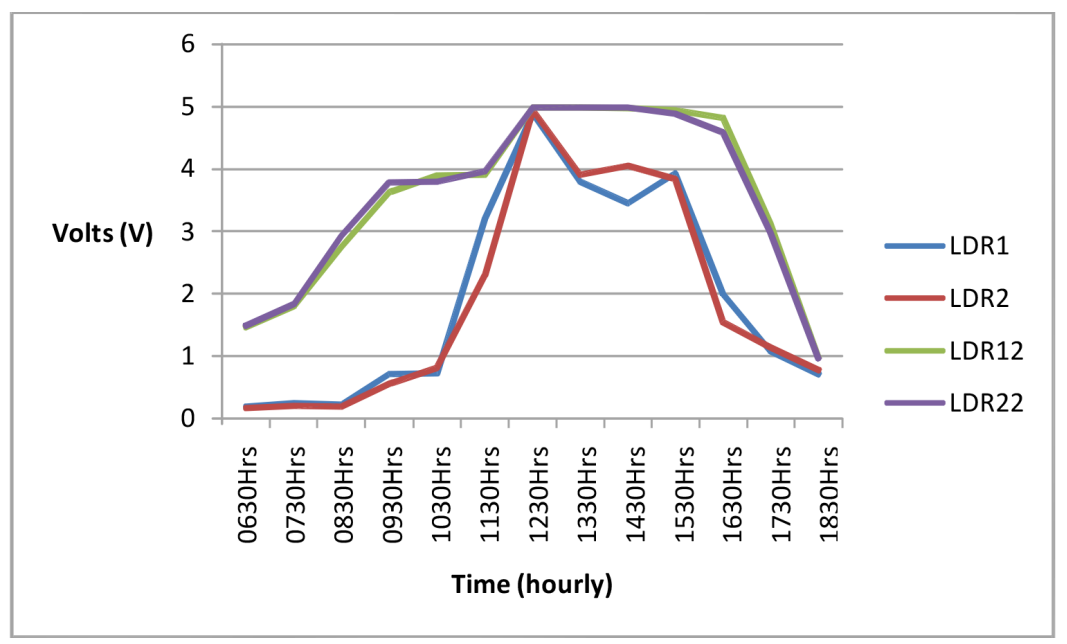

Fig. 9. Graph for cloudy morning and sunny afternoon of $6^{\text {th }}$ and $7^{\text {th }}$ April 2017

intensity of sunlight diminishes and the values obtained are less that those obtained during the day. After sunset, the tracking system is switched off to save energy. It is switched back on in the morning.

For the panel fitted with the tracking system, the values of the LDRs are expected to be close. This is because whenever they are in different positions there is an error generated that enables its movement. The motion of the panel is stopped when the values are the same, meaning the LDRs receive the same intensity of sunlight. For the fixed panel, the values vary because the panel is at a fixed position. Therefore, at most times the LDRs are not facing the sun at the same inclination. This is apart from midday when they are both almost perpendicular to the sun. 
Table 3. LDR outputs for bright sunny day on $2^{\text {nd }}$ April 2017

\begin{tabular}{|c|c|c|c|c|}
\hline & \multicolumn{2}{|c|}{ LDR readings for Fixed Panel } & \multicolumn{2}{c|}{ LDR readings for a Tracking Panel } \\
\hline Time & LDR1 & LDR2 & LDR12 & 1.487 \\
\hline $0630 \mathrm{Hrs}$ & 0.679 & 0.489 & 1.477 & 2.839 \\
\hline $0730 \mathrm{Hrs}$ & 0.792 & 1.061 & 3.804 & 3.990 \\
\hline $0830 \mathrm{Hrs}$ & 1.779 & 1.672 & 3.203 & 3.990 \\
\hline $0930 \mathrm{Hrs}$ & 3.167 & 1.199 & 3.990 & 4.149 \\
\hline $1030 \mathrm{Hrs}$ & 3.421 & 3.226 & 4.130 & 4.590 \\
\hline $1130 \mathrm{Hrs}$ & 4.604 & 3.208 & 4.500 & 4.990 \\
\hline $1230 \mathrm{Hrs}$ & 4.990 & 4.980 & 4.990 & 4.990 \\
\hline $1330 \mathrm{Hrs}$ & 4.980 & 4.990 & 4.888 & 4.985 \\
\hline $1430 \mathrm{Hrs}$ & 4.888 & 4.941 & 4.976 & 4.892 \\
\hline $1530 \mathrm{Hrs}$ & 4.413 & 3.878 & 4.941 & 4.790 \\
\hline $1630 \mathrm{Hrs}$ & 3.935 & 3.824 & 4.873 & 3.940 \\
\hline $1730 \mathrm{Hrs}$ & 2.639 & 2.639 & 3.964 & 2.815 \\
\hline $1830 \mathrm{Hrs}$ & 1.569 & 1.031 & 2.708 & \\
\hline
\end{tabular}

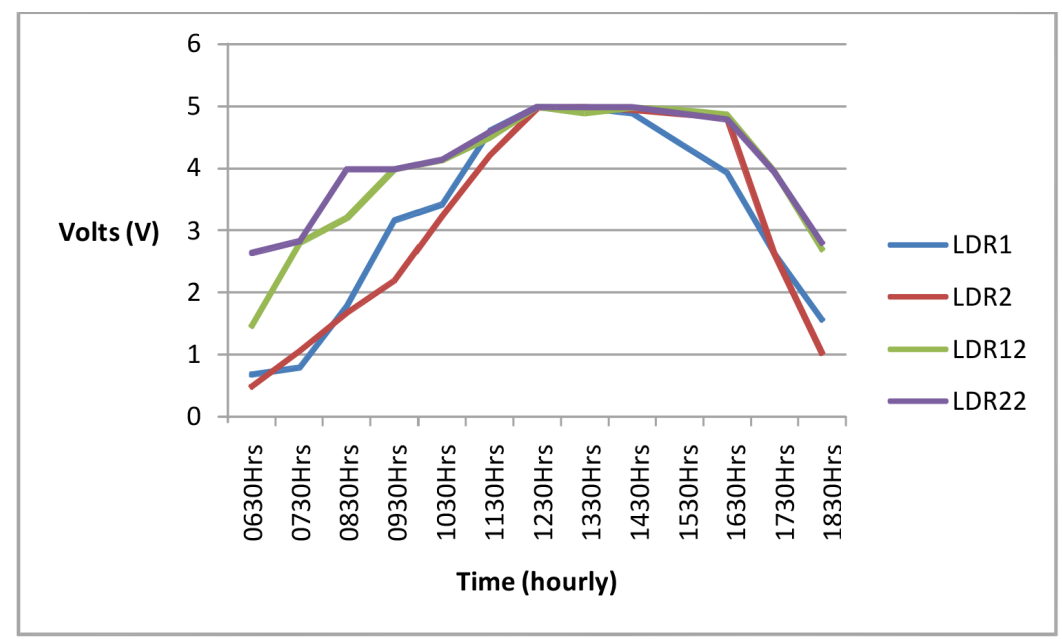

Fig. 10 Graph for bright sunny day of $2^{\text {nd }}$ April 2017

Days with the least cloud cover are the ones that have the most light intensity and therefore the outputs of the LDRs will be highest. For cloudy days, the values obtained for the tracking system and the fixed system do not differ too much because the intensity of light is more or less constant. Any differences are minimal. The tracking system is most efficient when it is sunny. It will be able to harness most of the solar power which will be converted into energy.

In terms of the power output of the solar panels for tracking and fixed systems, it is evident that the tracking system will have increased power output. This is because the power generated by solar panels is dependent on the intensity of light. The more the light intensity the more the power that will be generated by the solar panel. 
Table 4. Results for LDR outputs for a cloudy day on $12^{\text {th }}$ April 2017

\begin{tabular}{|c|c|c|c|c|}
\hline & \multicolumn{2}{|c|}{ LDR Readings for Fixed Panel } & \multicolumn{2}{c|}{ LDR Readings for a Tracking Panel } \\
\hline Time & LDR1 & LDR2 & LDR12 & LDR22 \\
\hline $0630 H r s$ & 0.147 & 0.117 & 0.274 & 0.244 \\
\hline $0730 H r s$ & 0.161 & 0.156 & 0.547 & 1.075 \\
\hline $0830 H r s$ & 0.274 & 0.205 & 1.090 & 1.276 \\
\hline $0930 H r s$ & 0.435 & 0.279 & 1.227 & 1.305 \\
\hline $1030 \mathrm{Hrs}$ & 0.572 & 0.547 & 1.271 & 1.569 \\
\hline $1130 \mathrm{Hrs}$ & 1.041 & 0.816 & 1.618 & 2.151 \\
\hline $1230 \mathrm{Hrs}$ & 2.175 & 1.965 & 2.165 & 1.794 \\
\hline $1330 \mathrm{Hrs}$ & 1.975 & 1.794 & 1.848 & 1.075 \\
\hline $1430 \mathrm{Hrs}$ & 1.119 & 1.623 & 1.090 & 0.943 \\
\hline $1530 \mathrm{Hrs}$ & 1.022 & 1.510 & 0.982 & 0.728 \\
\hline $1630 \mathrm{Hrs}$ & 0.543 & 1.017 & 0.762 & 0.538 \\
\hline $1730 \mathrm{Hrs}$ & 0.264 & 0.367 & 0.547 & 0.220 \\
\hline $1830 \mathrm{Hrs}$ & 0.064 & 0.103 & 0.327 & \\
\hline
\end{tabular}

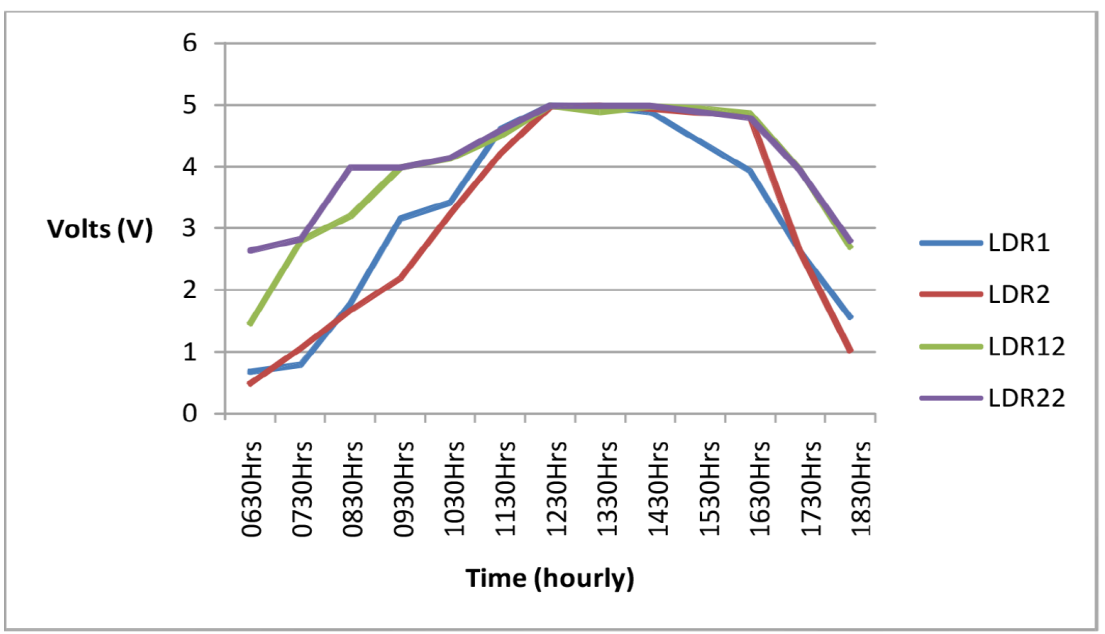

Fig. 11 Graph for a cloudy day on $12^{\text {th }}$ April 2017

The increase in efficiency can be calculated. However, it is important to note that there will be moments when the increase in power output for the tracking system in comparison with the fixed system is minimal, notably on cloudy days. This is expected because there will not be much difference in the intensity of sunlight for the two systems. Similarly, on a very hot day at midday, both systems have almost the same output because the sun is perpendicularly above. As such, both systems receive almost the same amount of irradiation.

A few values can be used to illustrate the difference in efficiency between the two systems. For a bright sunny day, we can take the averages for LDR22 and LDR2 for the entire day. We then use 5 as the base because it is the maximum value of the LDR output. It is calculated as a percentage and the 
two values compared. While this may not give the clearest indication of the exact increase in efficiency, it shows that the tracking system has better efficiency. The efficiency can be calculated as follows;

(Average value of LDR22 or LDR2/5volts)*100

For LDR22: $(4.027 / 5) * 100=80.54 \%$

For LDR2: $(2.856 / 5) * 100=57.14 \%$

The difference between the two values is $23.4 \%$. this means the LDR for the tracking system has an increased efficiency of $23.4 \%$.

\section{Conclusion}

A solar panel that tracks the sun was designed and implemented. The required program was written that specified the various actions required for the work. As a result, tracking was achieved. The system designed was a single axis tracker. While dual axis trackers are more efficient in tracking the sun, the additional circuitry and complexity was not required in this case. The work in this paper was implemented with minimum resources. The circuitry was kept simple, while ensuring efficiency is not affected.

\section{References}

[1] G. Deb and A. Roy, Use of solar tracking system for extracting solar energy, International Journal of Computer and Electrical Engineering, 2012, 4(1).

[2] O. Otieno, Solar tracker for solar panel, Graduation Project, University of Nairobi, Kenya, 2015.

[3] R. Banerjee, Solar tracking system, International Journal of Scientific and Research Publications, 2015, 5(3).

[4] S. Racharla, Solar tracking system-review, International Journal of Sustainable Engineering, 2017, 10(2).

[5] L.M. Giripunje, et. al., Solar tracking for maximum utilization of solar energy, International Research Journal of Engineering and Technology, 2017, 4(2).

[6] M. Jamilu, A review on solar tracking systems and their classifications, Journal of Energy, Environmental \& Chemical Engineering, 2017, 2(3). 